\section{Impetus from on high for community water fluoridation}

NHS England is signalling strongly that community water fluoridation is the optimum intervention to improve the oral health of children and tackle health inequality among disadvantaged communities.

The new impetus is fully supported by the Community Water Fluoridation (CWF) network, which is pressing for targeted water fluoridation in areas of high need. Dr Simon Hearnshaw, speaking for the CWF network, says that the latest unprecedented support from government inspires optimism that the first new scheme in a generation could get the go-ahead.

Health minister Jo Churchill referenced water fluoridation in the House of Commons, responding to a written question about plans for improving children's oral health. Meanwhile, Sir Paul Beresford, Conservative MP for the Mole Valley, and a dentist, gave a powerful speech in favour of community water fluoridation in Westminster.

New content ${ }^{1}$ has been added to the NHS England website and a whole page ${ }^{2}$ is dedicated to Dental Care and Fluoridation. According to NHS England, if 5-year-olds with the most tooth decay drank fluoridated water they would have $28 \%$ less tooth decay and be 45-68\% less likely to need teeth removed in hospital.

Dr Hearnshaw, Chair of the Local Professional Network (LPN) in Hull which instigated the CWF Network, said: 'NHS England is making the same case that is being made by us and by Public Health England. ${ }^{3}$ The whole philosophical thrust is towards the prevention of disease and in relation to dental decay, the most effective and cost-effective measure is water fluoridation.'

He welcomed the recognition on the new NHS England web page that support for CWF schemes at a local level by NHS representatives is important. Dr Hearnshaw believes this is a reference to the co-commissioning of feasibility studies by local authorities working with the NHS to provide a strong strategic and collaborative lead.

The CWF network would like NHS England to go one step further - it would like the recurring costs of water fluoridation to be funded by the NHS because it would benefit from the associated reduction in child hospital admissions for tooth extractions, estimated to be as much as $£ 50$ million annually in the UK.

Dr Hearnshaw continued: 'We have some way to go. Last month the USA celebrated 75 years of CWF. They have around $70 \%$ coverage, compared to only around $10 \%$ in the UK. All around the world new water fluoridation schemes are being adopted. We have not seen a new scheme in the UK since 1985.

\section{References}

1. NHS England. Menu of evidence-based interventions and approaches for addressing and reducing health inequalities. Available at: https://www.england.nhs.uk/ Itphimenu/ (accessed March 2020).

2. NHS England. Dental care and water fluoridation. Available at: https://www. england.nhs.uk/ltphimenu/better-care-for-health-conditions-for-dental-healthcare/ dental-care-and-water-fluoridation/ (accessed March 2020).

3. Public Health England. Research and analysis. Water fluoridation: health monitoring report for England 2018. Available at: https://www.gov.uk/government/publications/water-fluoridation-health-monitoring-report-for-england-2018 (accessed March 2020).

\section{Leeds university student wins dental skills competition}

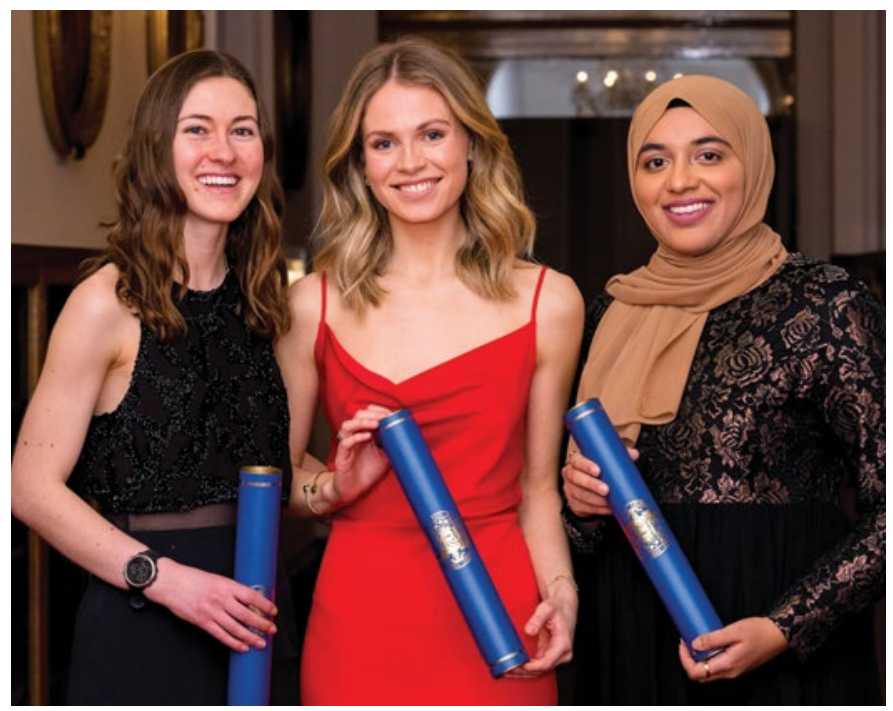

(I-r) Kirsty Skye Dickson, Emma Louisa Smith and Mishaim Aamir Mian

A dental student from Leeds University's Dental School has been crowned the winner of a prestigious competition aiming to discover the UK and Ireland's best undergraduate dentist.

Emma Louisa Smith, originally from Market Harborough, won the Dental Skills Competition, held by The Royal College of Surgeons of Edinburgh's Faculty of Dental Surgery in conjunction with sponsors Dentsply Sirona and supported by Dr Tom Bereznicki, beating off stiff competition from 14 other finalists.

Mishaim Aamir Mian from Cork University Dental School came in second place, followed by Kirsty Skye Dickson from the University of Glasgow Dental School in third place.

In a bid to uncover the best talent amongst undergraduate dentists, final year dental students have been competing in heats held in $18 \mathrm{UK}$ and Irish dental schools from October to December 2019.

Emma Louisa has won a trip to Chicago to attend the Chicago Dental Society Conference 2021 for winning The Grand Final, and Mishaim Aamir Mian is set to receive a trip to Ballaigues in Switzerland for placing second.

The dedicated student attended Robert Smyth Academy before going on to study dentistry at Leeds University.

The Grand Final of the competition was followed by a dinner in the Edinburgh College, where presentations were made to the winner and two runners-up. All participants in the competition received a certificate of participation and two years' affiliation with The Royal College of Surgeons of Edinburgh.

Professor Fraser McDonald, Dean of RCSEd's Faculty of Dental Surgery, said: 'This competition is part of our long term commitment to support and encourage the next generation of dental professionals. Fifteen aspiring young dentists took part, carrying out practical evaluations in areas that aren't often assessed in their normal environment.

'We would like to commend all the students who took part, and congratulate Emma Louisa for the well-deserved win.'

To find out more about the Dental Skills Competition, visit rcsed. ac.uk/skillscompdental. 